\title{
Reposicionamento Estratégico para Diferenciação por Meio da Educação Inovadora Strategic Positioning Differentiation by Innovative Education
}

\section{Sandra Cristina Silva Lourette Janguiê ${ }^{1}$ Márcia Athayde Moreira ${ }^{2}$}

\section{Resumo}

Esta pesquisa teve como objetivo geral analisar os resultados decorrentes da implantação de uma estratégia para a competitividade voltada à educação inovadora, em uma instituição privada de ensino básico brasileira. O levantamento dos aspectos teóricos possibilitou a delimitação metodológica para a realização da pesquisa de campo, o estudo de caso, para o que foram recolhidos documentos, além da observação in loco, da realização de entrevistas e aplicação de questionários, em um esforço de campo com duração de três meses, no período de outubro de 2019 a janeiro de 2020. Como resultados, pode-se observar que a escola caso foi uma escola tradicional cuja missão era preparar alunos para o vestibular, mediante ensino convencional em disputa de preços com as instituições concorrentes. Com a mudança de posicionamento, a escola caso repensou seu projeto pedagógico, implantou novas metodologias, trazendo o aluno para ser protagonista de sua aprendizagem, vivendo experiências que desenvolvem competências cognitivas e socioemocionais. Sob o ponto de vista estrutural, reformulou o projeto arquitetônico e investiu em novas tecnologias para ensino-aprendizagem. As estratégias de reposicionamento estratégico da escola caso em implantar uma educação inovadora se mostraram eficientes para atrair e fidelizar seus clientes, em um case de sucesso.

Palavras-chave: Educação Inovadora. Ensino Básico. Estratégia Organizacional. Diferenciação.

\section{Abstract}

This research aimed analyze results arising from a strategy implementation for competitiveness aimed at innovative education, in a private institution of basic education in Brazil. The survey of theoretical aspects enabled the methodological delimitation to carry out the field research, a case study, for which documents were collected, in addition to on-site observation, interviews and questionnaires, in a three month field effort, from October 2019 to January 2020. As a result, it can be observed that case school was a traditional school whose mission was prepare students for entrance exam, through conventional education in price dispute with the institutions competitors. With the change in positioning, the school, if it rethought its pedagogical project, implemented new methodologies, bringing the student to be the protagonists of their learning, living experiences that develop cognitive and socio-emotional skills. From a structural point of view, it reformulated the architectural project and invested in new technologies for teaching-learning. The strategic repositioning strategies of the case school enable an innovative education proved efficient in attracting and retaining its customers, in a case of success.

Keywords: Innovative Education. Basic education. Organizational Strategy. Differentiation.

Manuscript first received/Recebido em: 15/09/2021 Manuscript accepted/Aprovado em: 17/12/2021

\footnotetext{
1 Mestre em Administração pela Universidade da Amazônia. Diretora Geral da Escola Conecta. Recife, Pernambuco, Brasil. E-mail: sandra@escolaconecta.com.

2 Doutora em Controladoria e Contabilidade. Docente da Universidade Federal do Pará. Belém, Pará, Brasil. E-mail: mathayde@ufpa.br.
} 


\section{INTRODUÇÃO}

Parte-se da premissa de que o objetivo da educação não é mais ensinar coisas, porque elas estão por todo lado, na internet e nos livros. É preciso ensinar a pensar, despertar no indivíduo a curiosidade, criar alegria no pensar. Parte-se da premissa de que a missão do professor já não é dar respostas prontas, porque respostas prontas o aluno encontra na internet (Alves, 2019).

Nesse contexto, alunos precisam de uma educação ligada à vida, para viver melhor sob todos os seus aspectos, pois que se vive uma era de grandes transformações, não só no mundo do trabalho, mas também na vida social. A realidade atual, marcada por forte inovação, aumento dos competidores e da exigência dos clientes, tem influenciado a dinâmica competitiva dos mercados, provocando reflexões e reações em nível estratégico, a fim de garantir a manutenção da competitividade e da sustentabilidade dos negócios no longo prazo. Essa discussão abrange vários setores da economia, incluindo as instituições privadas de ensino básico.

Cortella (2014) reflexiona que os alunos da segunda década do século XXI não são mais os mesmos, no entanto, muitos professores continuam dando aula do mesmo jeito que davam há anos. Daí a importância de olhar a realidade, porque a educação lida com o futuro. Complementando esta ideia, Bacich, Tanzi Neto e Trevisani (2015) afirmam que um dos poucos, se não o único, serviço que ainda não passou por inovações é a educação. Logo, as escolas que desejam se manter competitivas, precisam se diferenciar, inovar, promover mudanças para o encontro de gerações na tentativa de falar a linguagem desses alunos para promover aprendizagens significativas dando sentido no aprender.

Assim, nessa perspectiva, observa-se a importância da escolha de uma adequada estratégia para a atuação das escolas de educação básica na atualidade. Porter (1986) afirma que a estratégia é determinante no que se refere aos resultados competitivos para uma organização, e ainda nesse sentido, a competitividade no mercado seria o alicerce para elevar os níveis de produtividade. Desse modo, uma organização que busca um diferencial no mercado está agindo de maneira estratégica e competitiva (Porter, 1986).

É fundamental o posicionamento da organização. Assim, instituições de ensino fundamental e médio, que constantemente confrontam desafios, estimuladas pelas mudanças no ambiente organizacional, buscam o (re)posicionamento estratégico. Observase uma grande concentração competitiva provocando a necessidade de melhorias de serviços demandando o desenvolvimento de uma estratégia eficaz de atuação (Sampaio, 2011), calcada em inovações no modo de ensinar e aprender, dando sentido para a escola no contexto da vida dos seus alunos, menos voltado para o vestibular e mais motivados pelos sentimentos e vivências (Alves, 2019). Ainda neste domínio deve-se considerar a tecnologia, o que naturalmente vem modificando o panorama das escolas, as quais terão outros papeis além de preparar o aluno para a entrada na universidade (Niskier, 2019).

Sabe-se que as estratégias, em geral, originam-se de processos de planejamento como também são resultantes de situações ou circunstâncias que emergem da própria 
dinâmica das organizações (Meyer Jr \& Mugnol, 2004). Nesse sentido, ressalta-se que, a busca contínua de alunos e maneiras de fidelizá-los, oferecendo inovações, constituem o desafio atual para o setor privado da educação básica (Sampaio, 2011).

Diniz (2020), observa que instituições privadas de ensino básico precisam pensar e (re)pensar suas estratégias de atuação, a fim de poderem se (re)posicionar no mercado, atendendo aos novos paradigmas educacionais e os novos mercados que dele surgem, a escola deve se alinhar a um modelo inovador para atingir o novo aluno da geração $Z$ e prepará-lo para o mercado de trabalho e para adequações para a vida cotidiana. Sobretudo com a inserção de novas tecnologias, adaptadas a serviço da aprendizagem, as quais contribuem para o desenvolvimento de paradigmas educacionais no Brasil (Pinto, 2019).

Diante do contexto que se apresenta, se define a questão norteadora desta pesquisa: Como se deu o processo de implantação de uma estratégia voltada à educação inovadora, capaz de dar novo sentido à aprendizagem, em uma instituição privada de ensino básico brasileira?

Assim, como objetivo para esta pesquisa, pretende-se analisar o processo de reposicionamento estratégico pelo qual uma instituição privada de ensino básico brasileira passou, na implantação de uma estratégia voltada para a competitividade por meio da educação inovadora.

Esta pesquisa se justifica por algumas razões. Primeiramente pela dimensão que a Educação Básica possui no Brasil. De acordo com o INEP (INEP, 2019), o censo escolar do ano de 2018 registrou 48.455.867 alunos matriculados na educação básica, desses, 8.995.249 eram alunos de escolas privadas. Um quinto dos alunos matriculados na educação básica no Brasil estão no ensino privado, um número bem expressivo de crianças e jovens em formação na educação brasileira. Também se justifica pelo esforço de estudar a estratégia no contexto das escolas de educação básica e a importância de se ter um adequado posicionamento estratégico para a organização, notadamente no contexto da escola privada de ensino básico, mercado de acirrada competição e fonte de inovação nas últimas décadas, acompanhando a revolução tecnológica pela exigência do mundo, com grande influência sobre crianças e jovens.

Segundo Cortella (2014) a mudança do mundo é veloz, mas muitas escolas ainda atuam no século XXI usando métodos que vêm do século XIX. É necessário, portanto, que sejam realizadas mudanças nas estratégias de atuação para que essa geração tenha o desejo aguçado de aprender e veja sentido na aprendizagem. Como contribuição, esta pesquisa demonstra na prática, que é possível quebrar paradigmas educacionais convencionais e inovar para favorecer o bem-estar dos alunos, o prazer em estudar, a curiosidade e a criticidade, favorecendo seu crescimento enquanto cidadão social e futuramente sua inserção no mercado de trabalho. 


\section{ASPECTOS TEÓRICOS}

\subsection{Educação Básica, Mudança de Paradigmas e Inovação Tecnológica}

Piangers e Borba (2019) trazem a seguinte reflexão: se no presente o descompasso entre escola e vida real já percebido, imagine o futuro. A pergunta dos autores é: Os ambientes de aprendizado estão acompanhando essa mudança? Todas essas revoluções tecnológicas irão tornar o trabalho obsoleto? $\mathrm{E}$, se isso acontecer, de que servirá uma escola que prepara multidões para o desemprego? $O$ mundo vem passando por grandes transformações não só de natureza tecnológica, mas também profissional - muitas profissões estão fadadas a desaparecer e outras surgirão, as ideias de sustentabilidade e o consumo responsável serão a cada dia mais incorporados ao comportamento das pessoas. O mundo quer pessoas executem múltiplas tarefas e saibam lidar com situações inesperadas (Piangers \& Borba, 2019).

Cortella (2014) ressalta que a cada dia, tem-se mais velocidade de comunicação, as relações, de mudanças de cenário, de conhecimento, de aprendizado obrigam a perceber as mudanças, de maneira a reorientar o processo de trabalho e a forma de como os alunos chegam à escola. Ele cita exemplos da carga de conhecimentos adquiridos através das mídias já na primeira infância. Diante a tantas mudanças de comportamento social e tecnológico, as escolas precisam investir em mudanças de ensino (provocando inovações) com o objetivo de adequar-se às novas gerações.

Nesse contexto pode-se citar Moran (2015) para quem a educação sempre foi misturada, híbrida, combinando espaços, tempo, atividades, metodologias e públicos. Pode-se aprender de múltiplas formas em todos os momentos. Moran (2015) também faz alusões que híbrido também pode ser um currículo mais flexível, que planeje o que é básico e fundamental para todos, e, que permita, ao mesmo tempo, caminhos personalizados para atender à necessidade de cada aluno, dando significado ao aprendizado (Moran, 2015), o que melhor ocorre quando se motiva os alunos em seu íntimo, quando eles encontram sentido nas atividades propostas.

Tavares (2019) aborda a inovação educacional como uma teia de significados que estão relacionadas às diversas concepções acerca do processo educacional, uma vez que afirma que a ideia de inovação se originou no ambiente empresarial, sendo que o melhor da educação preparará efetivamente os alunos para o mundo do trabalho, mas também os prepararia para se tornarem capazes de transformar o mundo do trabalho para melhor atender às necessidades das pessoas (Aithal \& Aithal, 2015).

Por outro lado, tem-se a educação convencional que atua na educação formal, com modelos básicos e com uma visão tradicional de ensino e aprendizagem. Enquanto isso, essas instituições só terão relevância quando apresentarem modelos mais eficientes, atraentes e adaptados aos alunos de hoje; quando superarem os modelos conteudistas predominantes das escolas tradicionais, em que tudo é previsto antes e é aplicado de uma forma igual para todos, ao mesmo tempo, de forma convencional (Barón, 2015). 
Nas escolas tradicionais a principal função é preparar o aluno para passar no vestibular, a educação não é focada no aluno, torna-o apenas o agente passivo da aprendizagem. Logo, a função dessa escola é transmitir conhecimentos, focar nos exercícios e na repetição dos conceitos, visando disciplinar a mente e formar o hábito de estudo.

Em contraponto, a educação inovadora coloca o aluno como protagonista do processo de aprendizagem, tornando-o ativo e persistente, promove o diálogo com as necessidades da sociedade, coloca os recursos tecnológicos como coadjuvantes da aprendizagem, ensina a resolver problemas e conflitos através do contato, discussão e reflexão acerca das habilidades socioemocionais, conscientização e cuidado com o meio ambiente e a sociedade, cultura, enfim trabalha o aluno para que ele tenha formação acerca do mundo, em uma visão que ultrapassa em muito o objetivo de passar no vestibular e poder estudar em uma universidade pública.

Nesse cômputo, Cardoso (2019) em seus estudos discute acerca da necessidade de inovação na metodologia do ensino, empregando o uso de tecnologias no processo de ensino e aprendizagem. A aplicação de tecnologias no processo pedagógico permite aos professores inovar na arte de ensinar, valorizando o conhecimento científico e tecnológico acrescentando ao processo de ensino e aprendizagem: criatividade, entusiasmo e experiências virtuais, isto é, adentrando em um processo de inovação na educação (Cardoso, 2019).

Corroborando estudos de Cardoso (2019), Pereira e Mendes (2019), no âmbito do ensino básico, discutem acerca do uso de tecnologias na educação básica em duas escolas de campo das quais foram promovidas ações interdisciplinares e de valorização cultural. Como resultado da experiência, constatou-se que tais tecnologias e mídias podem ser integradas e utilizadas enquanto ferramentas pedagógicas relevantes e inovadoras (Pereira \& Mendes, 2019).

Nessa mesma linha de raciocínio, Conforto, Cavedini, Miranda e Caetano (2018) discutem a implementação da ação pedagógica Oficina de Pensamento Computacional no âmbito da educação básica, em Porto Alegre. Nesse sentido, concluem que é preciso criar espaços para que estudantes possam vivenciar experiências interessantes na resolução de problemas, isto é, reforçando a importância de instrumentos tecnológicos na educação básica (Conforto, Cavedini, Miranda \& Caetano, 2018).

Ainda nesse contexto, Benedet, Réus e Lunardi (2019) desenvolvem uma experiência em formação continuada mediada pelas tecnologias da informação e comunicação, tendo como público-alvo 40 professores da Educação Básica de um município do sul de Santa Catarina, ressaltando a importância ao longo da formação em como mediar a aprendizagem desde a educação infantil até as séries finais do Ensino Fundamental com o uso das tecnologias. Com isso, evidenciou-se que os professores necessitam aprender sobre tecnologias educacionais impactando efetivamente o trabalho em sala de aula e trazendo um novo paradigma de educação (Benedet, Réus \& Lunardi, 2019). 


\subsection{Prazer, Curiosidade e Criticidade no Âmbito da Aprendizagem}

No século 21, a escola tem o desafio de desenvolver uma proposta que estimule o prazer em estudar, a curiosidade, a criatividade e o senso crítico. De acordo com Meira (2017), a missão da escola não deve ser a de apenas ensinar, mas de criar cenários de aprendizagem baseados em diálogo e diversão. Nesse sentido, a sala de aula enrijece o aprendizado e, da forma como foi concebida, a escola impõe um modelo que não incentiva a criatividade e dá pouco espaço para que o professor promova transformações. A escola tem que ser mais divertida (Meira, 2017).

Logo, a construção do prazer do aluno pela escola depende de um sistema que proponha ao estudante experiências de aprendizagem baseada em desafios que o levem a analisar ideias com criticidade, discutir diferentes pontos de vista, compartilhar saberes e buscar soluções criativas (Mosé, 2013). Dessa forma, o aluno percebe o sentido de aprender, compreende que a aprendizagem ocorre de modo colaborativo, interativo e lúdico. É inevitável, neste processo, um alinhamento entre os objetos de conhecimento e o universo social, político, econômico e pessoal no qual o aprendente está inserido.

McGrath (2019) assevera que essa reengenharia didática que rompe com a uma escola pensada e organizada nos moldes da sociedade industrial coloca o aluno na condição de protagonista da aprendizagem, o leva a aprender a aprender e o faz entender para que aprender. Nesse contexto, o professor passa exercer o importante papel de mediador da aprendizagem, com o desafio de estimular a curiosidade do aluno, sua busca pelo conhecimento (McGrath, 2019).

É importante destacar que, nesse processo, o papel do estudante é gerar conhecimento, e não apenas se apropriar e encher sua mente com informações e conceitos. Ele desenvolve a capacidade de formular, negociar e defender ideias e pontos de vista, decisões comuns. Também se inicia, assim, o processo de construção do senso crítico e de desenvolvimento de habilidades socioemocionais.

Cabe ressaltar que durante séculos a educação básica teve como foco o desenvolvimento de habilidades cognitivas. Freire no início do século XXI já afirmava que a educação se tornaria um ato de depositar, em que os educandos são os depositários e o educador o depositante (Freire, 2000), onde a formação conteudista não dá espaço para a criatividade, a curiosidade e o afloramento das emoções.

Entretanto, no mundo em que a sociedade vivencia grandes transformações sociais, culturais, tecnológicas e econômicas, novas responsabilidades recaem sobre a escola. Além de desenvolver competências cognitivas, que representam a amplitude do conhecimento construído e o uso deste saber na identificação e solução de problemas, a escola passa a ter o compromisso de criar meios possibilitem a formação global do aluno, na qual o desenvolvimento das competências socioemocionais é tão importante quanto o daquelas.

De modo geral, as competências socioemocionais consistem em um conjunto de habilidades fundamentais para que o indivíduo possa se relacionar com os outros e consigo mesmo, entender e administrar emoções, traçar e atingir objetivos, tomar decisões 
autônomas e responsáveis e enfrentar situações adversas de maneira criativa e construtiva, inserindo a abertura para novas experiências, a consciência, a extroversão, a amabilidade e a estabilidade emocional (Ackerman, 2019).

É possível afirmar que o ensino de habilidades socioemocionais na escola contempla um dos pontos principais da práxis da psicologia escolar e educacional que é a perspectiva preventiva de atuação. Além de estimular um desenvolvimento emocional positivo, as aulas dos programas socioemocionais podem ajudar na observação de sinais de alerta de possíveis situações críticas que precisem ser cuidadas pela escola e pela família, assim, o professor deve trabalhar em relação próxima e dinâmica com os demais setores da escola (Goleman \& Senge, 2015). Um ambiente acolhedor e emocionalmente saudável e seguro pode exercer uma diferença fundamental na vida de crianças e adolescentes.

Os novos paradigmas educacionais para o século XXI exigem mudanças no posicionamento estratégico das instituições de ensino, para além da disputa por alunos baseada em preços, é preciso um reposicionamento baseado na diferenciação e personalização dos serviços prestados.

\subsection{Estratégia Organizacional para a Diferenciação}

No âmbito das organizações, estratégia é definida como a determinação dos objetivos e metas para o longo prazo de uma organização, com a adoção de ações e a alocação dos recursos necessários para realização destas metas (Mintzberg, 1978). Anthony e Govindarajan (2006, p.92) definem estratégia como "[...] a direção geral em que uma organização planeja mover-se para atingir seus objetivos".

Mintzberg, Ahlstrand e Lampel (2000) afirmam que a estratégia apresenta a vantagem de mapear o curso da organização, de promover a coordenação entre as atividades, de permitir que as pessoas entendam sua organização e a distingam de outras. Nesse sentido, uma estratégia pode surgir como resposta a um estímulo ou mesmo por um processo deliberado, sendo denominada de estratégia pretendida aquela em que os administradores planejam baseado em análises da dinâmica de competitividade, nos recursos e capacidades da organização (Mintzberg, Ahlstrand \& Lampel, 2000). Cabe destacar que a evolução da forma como a estratégia é pensada e operacionalizada nas organizações, está relacionada às modificações que ocorrem no contexto socioeconômico no qual as organizações estão inseridas (Alves, 2010).

Assim, as estratégias podem surgir de estruturas formais, da visão da organização, de suas crenças e valores, de suas restrições e contingências. Nessa visão, Porter (1986) identificou que em geral cada empresa possui uma estratégia única, relacionada com sua estrutura e perspectivas. No âmbito dos estudos de Porter (1986) pode-se dizer que existem três estratégias genéricas internamente consistentes que são utilizadas pelas organizações, as quais são: liderança em custo total, diferenciação e enfoque.

Nesse sentido, no enfoque estratégico para a diferenciação, a empresa busca diferenciar o seu produto ou serviço, gerando algo que seja considerado inovador, único ou 
inusitado no âmbito do seu setor de atuação. Porter (1986) afirma que a diferenciação pode assumir muitas formas tais como: projeto ou imagem da marca, inovações tecnológicas, peculiaridades na prestação dos serviços, serviços sob encomenda, rede de fornecedores e outras dimensões que a diferenciem das demais organizações concorrentes.

Assim, quando pensa em se diferenciar, a empresa deve utilizar múltiplas dimensões a fim de se destacar, podendo se destacar ao mesmo tempo pela qualidade e durabilidade de seus produtos, por um atendimento de qualidade, por uma ampla estrutura de revendedores, um bom pós venda, mas principalmente pela qualidade de seus produtos e serviços, incentivando o empreendedorismo e a criatividade de seus colaboradores, coordenando eficientemente as funções de pesquisa e desenvolvimento, entre diversas outras combinações (Porter, 1986; Barros Neto, 1999). Uma empresa que se posiciona por sua diferenciação busca o isolamento contra os seus concorrentes, fidelizando os clientes, se tornando menos sensíveis ao preço de venda agregando valor aos seus produtos e serviços (Porter, 1986).

Considerando o paradigma educacional vigente, é necessária uma forte reflexão para a busca de novos caminhos e alternativas para a manutenção da competitividade das escolas privadas de ensino básico, e neste contexto, a diferenciação como alternativa estratégica de atuação deve impulsionar novos modelos de atuação e gestão escolar, conciliando o ideário de formação do cidadão por meio da perpetuidade do negócio. Sem pretensão de longo prazo, há que se saber que a diferenciação também precisa se inovar, $\mathrm{e}$ a inovação da diferenciação deve seguir acompanhando os novos paradigmas educacionais e tecnológicos, em um sistema recorrente que não se acomoda, mas atua em favor da organização e das futuras gerações.

\section{PROCEDIMENTOS METODOLÓGICOS}

Utiliza-se nesta pesquisa o estudo de caso como método para conduzir a investigação de campo. Como estudo de caso, a presente pesquisa é classificada como exploratória quanto aos objetivos e qualitativa quanto a abordagem do problema, a partir de múltiplas fontes de evidência (Flick, 2009). Além do levantamento e análise dos aspectos teóricos, a investigação de campo se deu por meio de entrevistas, observação in loco e análise documental.

Conforme se pode observar no Protocolo de Estudo de Caso (Quadro1), a primeira etapa da pesquisa foi a identificação da empresa participante do estudo. Neste sentido foi escolhida uma Instituição de Ensino Básico (Educação Infantil, Ensino Fundamental e Médio), situada no município de Recife, no Estado de Pernambuco, Brasil.

A escolha desta instituição de ensino se deu pelas suas características, por ter passado recentemente por um processo de reestruturação inovadora de sua gestão, com mudança de postura estratégica, antes voltada para liderança em custos, e atualmente focada na diferenciação, provocada por um processo radical de inovação. 
Primeiramente dados públicos foram colhidos em seu sítio na internet, e, após a identificação, a escola foi contactada e aceitou participar da pesquisa em 04 de outubro de 2019. A pesquisa de campo teve início na mesma data do aceite, e durou até 10 de janeiro de 2020.

Quanto ao critério de inclusão dos indivíduos que participaram desta etapa da pesquisa, incluindo o diretor, coordenadoras, psicóloga e professores, foram incluídos aqueles que trabalharam na escola desde o ano de 2017, início das mudanças estratégicas, e permaneceram por todo o ano de 2019, e aceitaram participar da pesquisa.

Foram aplicados questionários para 43 alunos, sendo 21 alunos do $6^{\circ}$ ano do ensino fundamental e 22 alunos da $1^{\text {a }}$ série do ensino médio, tendo sido questionados sobre a percepção acerca do caráter inovador da escola; o que eles consideram mais inovador na escola; e, o que eles mais gostam na escola. Foram analisados os documentos, notadamente fotos, que denotam as alterações realizadas na entidade de forma comparativa nos anos de 2017, 2018 e 2019.

Por fim, foi realizada a observação como forma de verificar na instituição a existência física das alterações propostas em sua estratégia.

A implantação dos processos de inovação que levaram à mudança do posicionamento estratégico da escola foi realizada ao final do ano de 2018, para que o ano letivo de 2019 já se iniciasse com as alterações propostas. Mas a percepção da necessidade de mudança se deu no ano de 2017. Dessa forma, o processo de mudança se deu em três anos, sendo o ano de 2017 o do início, o ano de 2018 o da implantação do projeto e o terceiro ano, 2019, o primeiro a se colher os frutos da mudança.

Quadro 1. Protocolo para Execução do Estudo de Caso

\begin{tabular}{|l|}
\hline 1 Identificação e reconhecimento da empresa participante do estudo \\
\hline Estudo das informações públicas da empresa selecionada \\
\hline Justificativa da escolha e o contato com a empresa \\
\hline Identificação do modus operandi da organização \\
\hline \\
\hline $2^{\circ}$ Realização de entrevistas semiestruturadas (gestores, professores, e equipe multidisciplinar) \\
\hline Estruturação dos roteiros de entrevista \\
\hline Aplicação das entrevistas \\
\hline \\
\hline $3^{\circ}$ Aplicação de questionários aos alunos \\
\hline Estruturação das questões da coleta \\
\hline Realização da coleta em campo \\
\hline \\
\hline $4^{\circ}$ Análise documental \\
\hline Levantamento de documentos para análise das mudanças ocorridas \\
\hline
\end{tabular}


$6^{\circ}$ Compilação e análise dos dados obtidos

Análise do conteúdo com base nos objetivos do trabalho

Comparação dos achados empíricos com os aspectos teóricos levantados

Fonte: Elaborado pelos autores, 2019.

Quanto as técnicas de análise de dados, pode-se dizer que: as entrevistas e os relatos de micro cases foram transcritos e tiveram seu conteúdo analisados. Os resultados dos questionários aplicados aos alunos foram tratados com estatística descritiva simples. A análise documental e a observação foram relatadas em papéis de trabalho e posteriormente organizadas em textos. Os dados, informações e imagens coletadas serviram como elementos complementares para a consecução dos objetivos do estudo.

\section{APRESENTAÇÃO E ANÁLISE DOS RESULTADOS}

De acordo com o relato de seus diretores, inicialmente concebida para atuar com base no enfoque estratégico de liderança por custos (Porter, 1986) a escola, inaugurada em 1999, tinha como meta oferecer uma educação centrada na preparação para o ingresso do aluno no ensino superior. A estrutura física refletia o tradicionalismo do serviço ofertado: o espaço de $7000 \mathrm{~m}^{2}$ apresentava 22 salas de aula com mobiliário tradicional. Estrutura que permaneceu ativa até o ano de 2018 pode ser vista na Fotografia 01.

O referido estabelecimento de ensino atendia a alunos de 2 a 17 anos, a maioria pertencente à uma oscilação de classe social, moradores das adjacências. O número médio de alunos, nos anos de funcionamento, oscilou entre 600 e 900 alunos. A escola contava com um corpo docente formado por 65 profissionais graduados.

Após 18 anos de funcionamento, foi percebido que o serviço oferecido pelo estabelecimento não se diferenciava das demais instituições de ensino, além disso, havia uma inquietação decorrente da disparidade entre o discurso acadêmico sobre educação para o século 21 , as mudanças sociais e o modelo de educação que a escola ainda apresentava. Também havia uma política excessiva de concessão de descontos, o que reduzia o valor da anuidade escolar em até $25 \%$. Dessa forma, era necessário mudar o posicionamento estratégico da escola, buscando uma nova estratégia, baseada na diferenciação (Porter, 1986) de seus produtos e serviços entregues.

O processo de mudança do enfoque estratégico, de concepção e criação da nova escola em novos paradigmas durou 18 meses, e se iniciou em meados do ano de 2017. Esta primeira etapa de idealização da nova escola correspondeu a uma série de visitas a escolas nacionais e internacionais indicadas como inovadoras. $O$ objetivo era poder conhecer as propostas pedagógicas, os espaços físicos, as inovações tecnológicas e o grau de motivação dos estudantes destas escolas.

A diretoria da escola fez o lançamento oficial para os docentes em agosto de 2018 e, no dia seguinte, para a comunidade de alunos e familiares. Após os encontros iniciais, 
começou a ser realizada uma extensa ação de marketing. Desde então, começou o trabaIho de formação do quadro docente primeiramente online, através da disponibilização de e-books e artigos sobre inovação, metodologias ativas, nova BNCC e habilidades socioemocionais, e posteriormente de forma presencial, através de palestras, oficinas, cursos sobre educação maker, neurociência e aprendizagem, combate ao bullying, tecnologias na educação e sistemas.

\subsection{Eixos metodológicos da Escola Caso: Protagonismo do Aluno e Vivências de} Aprendizagem

Por meio da análise da proposta pedagógica da escola caso, foi observado que em todas as etapas da educação básica, o currículo se propõe a desenvolver competências, as quais compreendem a capacidade de mobilizar, articular e colocar em prática conhecimentos, valores, atitudes e habilidades, seja no aspecto cognitivo, seja no aspecto socioemocional, ou na inter-relação dos dois, em acordo com os pressupostos defendidos por Ackerman (2019).

As evidências indicam a inovação no currículo aproximando o cotidiano dos alunos da vivência escolar. A análise dos documentos indicou que a escola caso se propõe a desenvolver uma metodologia centrada nos pilares da educação estabelecidos no Relatório para UNESCO da Comissão Educação para o século XXI. Nessa perspectiva, os educadores da escola caso são incentivados pelos gestores pedagógicos a partirem da concepção de que o aluno é o protagonista do processo de aprendizagem significativa e investem em ações, metodologias e estratégias diversificadas a fim de atender a diversidade de necessidades discentes; motivar e engajar os alunos nas aprendizagens; dispor de recursos didáticos e tecnológicos para apoiar o processo de ensino e aprendizagem; participar ativamente de programas de formação docente.

Essas ações favorecem as vivências de aprendizagem, como o projeto Learning Experience - a família vivendo a escola, planejado com o objetivo proporcionar aos pais e responsáveis a vivência de experiências de aprendizagem juntamente com os filhos. A Figura 1 apresenta momentos do desenvolvimento do projeto.

\section{Figura 1. Projeto Learning Experience}

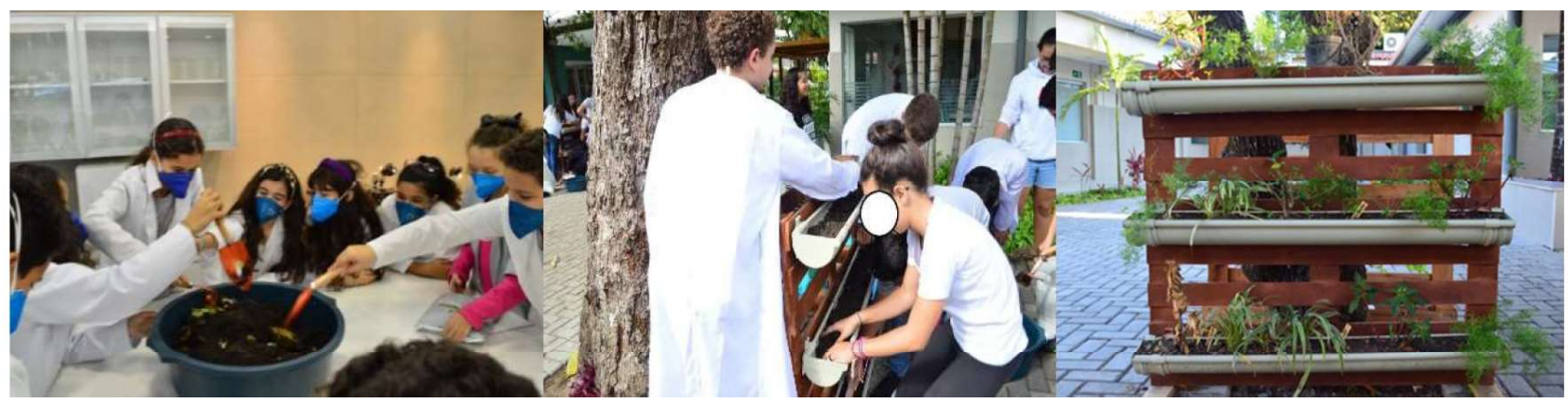

Fonte: Acervo da Instituição, 2019.

O projeto previa a produção de composteiras: usando a metodologia da sala de aula invertida, os professores sugeriram que os alunos buscassem conhecimento sobre a 
construção de composteira. Em seguida, compartilharam entre o grupo, o conhecimento construído na primeira etapa. Nas aulas de ciências naturais, identificaram os resíduos para a produção de composto. O projeto justifica que ao proporcionar a comunidade vivências reais de como os professores organizam e realizam suas aulas, a família consegue ampliar, para além dos muros da escola, as oportunidades de aprendizagem dos filhos. "Por mais que a gente seja informada, no ato da matrícula, como a escola funciona e a metodologia dos professores, viver essas experiências junto aos filhos faz com que possamos entender e orientá-los melhor nas atividades em casa", afirmou uma mãe de dois alunos espontaneamente quando informalmente fora questionada sobre o projeto.

\subsection{Influência das Alterações Estruturais Arquitetônicas}

A construção de um novo projeto pedagógico apontava necessidades de mudanças do espaço físico. Ele precisava de inovações arquitetônicas para promover conforto além de influenciar diretamente no desenvolvimento do projeto didático. $\mathrm{O}$ arquiteto indiano Prakash Nair (2011) considera que a evolução das metodologias de ensino com a incorporação das novas tecnologias em sala de aula, precisa vir acompanhadas das mudanças físicas no ambiente escolar para que a escola atenda as demandas dos alunos atuais.

A necessidade de um ambiente escolar adequado começa desde a educação infantil uma vez que a primeira infância requer espaços físicos adequados. Daí a importância de os arquitetos responsáveis se apropriarem da proposta escolar e, assim, criarem espaços que dialogam com o projeto. Esta etapa de adequações estruturais considerou princípios de sustentabilidade; respeito ao patrimônio histórico, visto que o espaço da nova escola conta com um casarão do século 19, tombado pelo IPHAN; as normas de acessibilidade, uma vez que a nova instituição se dispõe à inclusão; e principalmente o entendimento de que todos os espaços são espaços de aprendizagem o qual consiste em uma ruptura da ideia de que a aula só ocorre em locais específicos com carteiras escolares e quadro.

O alinhamento desses fatores resultou em um projeto arquitetônico propício à vivência de experiências diversas de aprendizagem que antes não existiam na instituição, os quais podem ser citados: Laboratório Maker como um espaço de criatividade e experimentação. A imersão, a compreensão do desafio, a ideação, a prototipação, a testagem são etapas desses projetos que possibilitam o desenvolvimento de diversas habilidades; 2) Oficina de Gastronomia, espaço promove experiências de aprendizagem significativa no formato de cozinha, favorece aulas práticas onde os alunos trabalham reações químicas das mais complexas a mais simples; 3) Sala Fórum, um espaço criado com o objetivo de o estudante viver experiências de aprendizagem baseadas no debate, na discussão sobre temas globais, em seminários e entrevistas, onde o aluno desenvolve também sua oratória, habilidade importante para o cidadão de um mundo midiático, em que a comunicação em massa é tão valorizada; 4) Sala de Leitura e Estudo, local onde são realizadas contações de história, estudo orientado e grupos de pesquisa; 5) Brinquedoteca e o parque infantil são espaços de aprendizagem fundamentais principalmente para o 
desenvolvimento das crianças de educação infantil: conviver, brincar, participar, explorar e expressar, na vivência ativa com outras pessoas e objetos, que possibilita descobertas pessoais em espaços onde são realizados trabalhos individualmente ou em pequenos grupos; e, 6) Laboratório Multidisciplinar, o qual, assim como o espaço maker, é mais um local para experimentação na escola, contando com vidraria, simuladores e aparelhagem específica. A Figura 2 reúne um conjunto de fotos dos espaços arquitetônicos observados in loco, durante as visitas à escola.

Figura 2. Espaços escolares inovadores da escola caso.
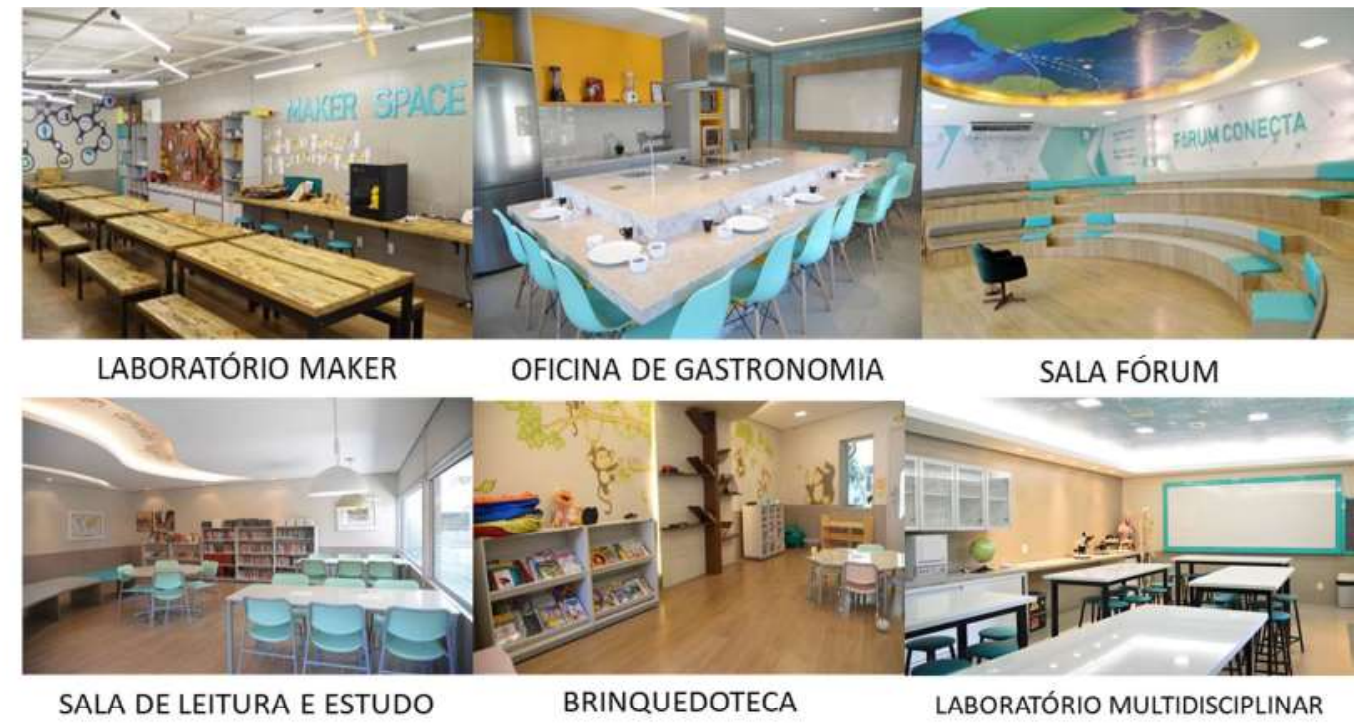

Fonte: Dados da pesquisa, 2019.

Entre as inovações arquitetônicas, destaca-se a sala de aula. O fato de a escola em estudo ter em sua proposta pedagógica as metodologias ativas como eixo metodológico foi decisivo para que o projeto arquitetônico apresentasse salas com mobília flexível em todas as séries da educação básica, além de sinal de wi-fi, datashow, armários.

A Figura 3 apresenta um comparativo entre o modelo de sala aula do ano de 2017 (convencional) e a sala de aula inaugurada em 2019.

Figura 3. Comparativo entre os modelos de sala de aula 2017/2019

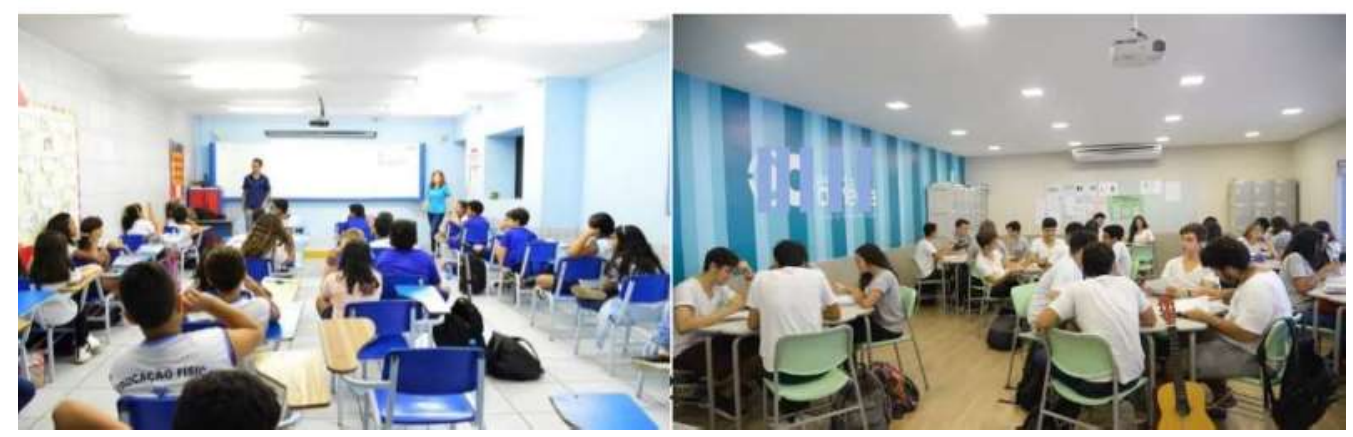

Fonte: Acervo da Instituição e dados da pesquisa, 2019. 
De fato, não é o inerte da mobília em si, mas o uso dinâmico do espaço pelo professor e estudantes. Um exemplo disso foi uma experiência realizada pela professora de matemática com os alunos do $6^{\circ}$ ano. Para abordar o objeto de conhecimento "fração", a professora promoveu uma aula na oficina de gastronomia onde ensinou o conceito de fração à medida que os alunos aprendiam também a fazer pizza. As medidas fracionárias da receita e a degustação final possibilitaram a construção do conhecimento sobre o tema. Com essa atividade, ficou muito claro, segundo relatos espontâneos dos alunos, que a aprendizagem foi muito além do conteúdo matemático, visto que tiveram a oportunidade de desenvolver habilidades como o trabalho em grupo, com respeito ao ritmo de cada um. A mudança estrutural, aliada à mudança dos paradigmas educacionais competem para a verdadeira diferenciação da escola.

\subsection{A Percepção dos Alunos e Corpo Técnico Acerca das Mudanças Estratégicas}

Conhecer a percepção do cliente (alunos) em relação às estratégias, que, no conceito de Anthony e Govindarajan (2006), indicam como a organização se move em direção aos objetivos, é fundamental para que os gestores possam dimensionar o impacto das estratégias e a necessidade de alteração da rota em busca da realização das metas.

Nesse sentido, durante o período da realização desta pesquisa, foi aplicado questionário a duas turmas, tomando como critério o fato de serem de iniciais de ciclos da educação básica: a primeira, o $6^{\circ}$ ano do ciclo das séries finais do ensino fundamental; e a segunda, $\mathrm{o} 1^{\circ}$ ano do ensino médio. Foi utilizada a plataforma de formulários Google e os estudantes responderam eletronicamente ao questionário.

O Gráfico 1 apresenta a percepção sobre o caráter inovador da escola. Dos 21 alunos do $6^{\circ}$ ano participantes da pesquisa, 15 estudantes consideram que a escola caso é inovadora e seis identificam parcialmente o caráter inovador. $\mathrm{Na} 1^{\text {a }}$ série do Ensino Médio, a maioria também reconhece a escola como inovadora: dos 22 alunos, que responderam, 17 reconhecem a escola caso uma instituição inovadora e cinco consideram-na parcialmente inovadora. Nenhum dos participantes optou em negar o caráter inovador do estabelecimento em estudo.

\section{Gráfico 01 - Percepção sobre o caráter inovador da escola}

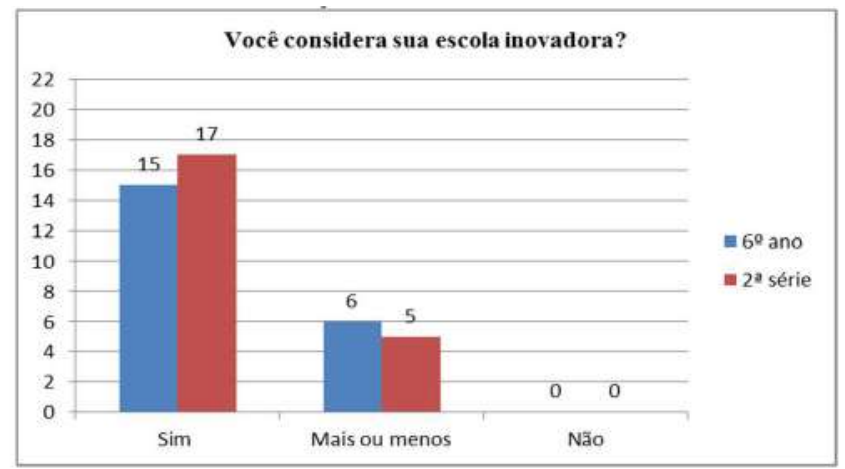

Fonte: Dados da Pesquisa, 2019 
Também os alunos foram questionados acerca do que eles consideram mais inovador na escola caso. Dos alunos do sexto ano, que responderam à pesquisa, 18 responderam que consideravam os espaços físicos, o modo como os professores organizam e realizam as aulas e o uso da tecnologia como os itens mais reveladores da escola caso (cabe ressaltar que eles poderiam escolher mais de um item). Já dos 22 alunos da $1^{\text {a }}$ série do ensino médio, 20 consideram os espaços físicos e o uso de tecnologia o que há mais inovador na escola. O Gráfico 2 apresenta.

\section{Gráfico 02 - O que considera mais inovador na escola}

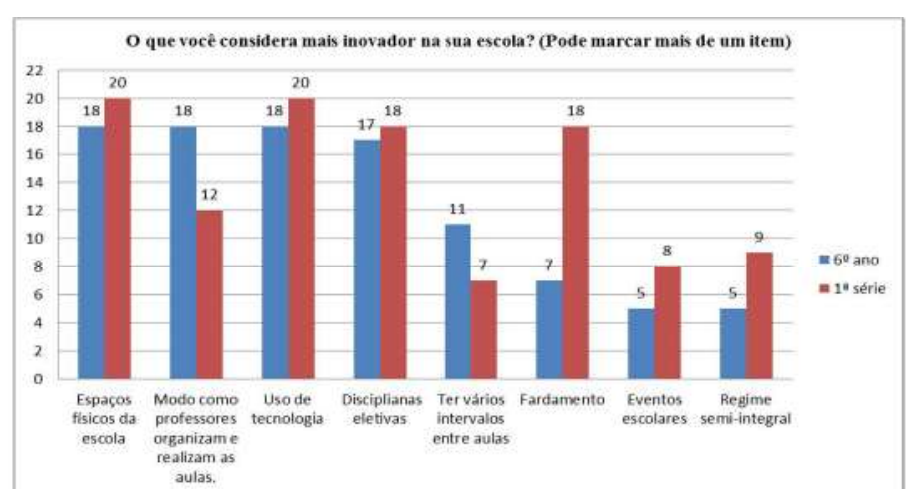

Fonte: Dados da Pesquisa, 2019.

A pesquisa realizada também interrogou os alunos sobre o que eles mais gostam na instituição, apresentado no Gráfico 3. Os 21 participantes do $6^{\circ}$ ano foram unânimes em apontar os recursos tecnológicos. Na sequência decrescente, também marcaram esportes, aulas práticas e ambiente ou convivência, como itens que mais os agradam. Para 20 dos 22 estudantes da $1^{\text {a }}$ série do ensino médio, a estrutura física da escola é o item de que mais gostam. Na sequência decrescente, gostam dos recursos tecnológicos disponibilizados, do ambiente e das aulas práticas.

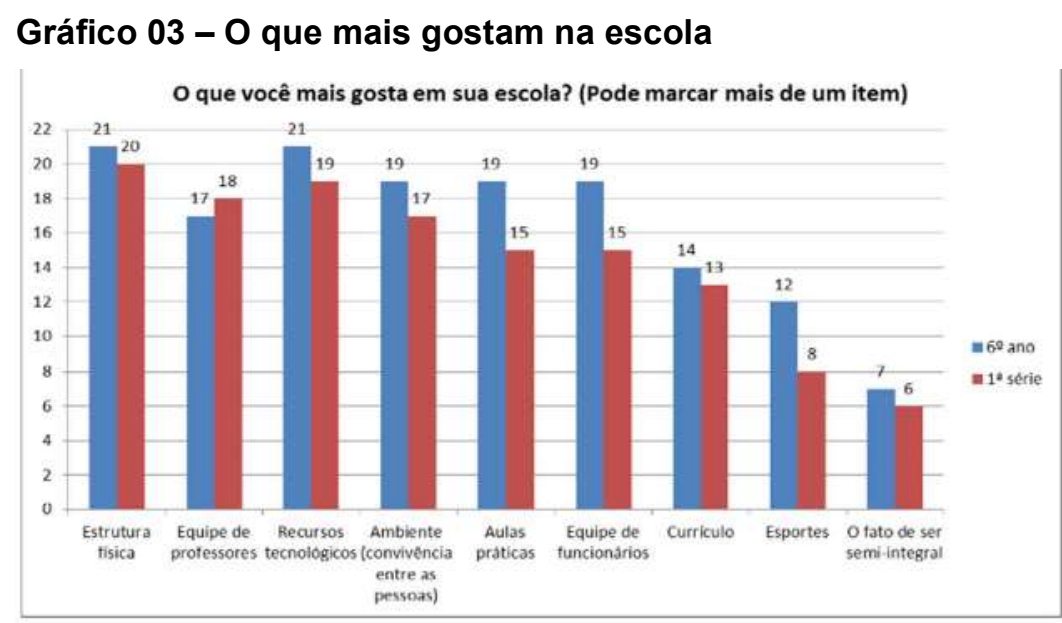

Fonte: Dados da Pesquisa, 2019 
Os resultados apontam que a escola caso conseguiu sensibilizar o corpo discente em relação aos propósitos educacionais de sua proposta, visto que, nos dois grupos analisados, a maioria dos participantes reconhece a instituição como inovadora. Quando se pensa que a inovação educacional engloba um conjunto de fatores norteados pelos princípios da autoaprendizagem, da ênfase no fazer, no autoconhecimento e nas relações interpessoais, enxerga-se nos Gráficos 2 e 3 uma relação coerente com o resultado do Gráfico 1.

A tecnologia é uma das maiores referências de inovação que compõe o imaginário popular. No discurso acadêmico também a tecnologia ganha espaço como recurso utilizado por alunos e professores para promover aprendizagens novas e mais amplas. Na escola caso, a tecnologia integra os planos de ensino e motiva a aprendizagem, o que comprova o fato de o uso desses recursos aparecer, na pesquisa, como um dos itens dos quais os alunos participantes mais gostam e que servem para identificar a instituição como inovadora. Essa relação de simpatia do alunado à inserção dos recursos tecnológicos no espaço escolar possibilita ferramentas para a aprendizagem. É muitas vezes por meio desses instrumentos que o estudante vai conquistando o protagonismo de sua aprendizagem.

Ainda os resultados da pesquisa mostram que a arquitetura da escola caso figura não só como um índice para que os participantes considerem a instituição como inovadora, mas também um dos quais eles mais gostam. Percebe-se também que a mudança metodológica promovida pelos professores foi reconhecida pelos alunos como uma referência de inovação. Sendo que na turma do ensino fundamental, em que há maior número de aulas práticas e interativas, esse item chamou muito mais atenção dos alunos do que no ensino médio.

Quando a equipe técnico-pedagógica foi entrevistada, a percepção mais evidente em relação à mudança de estratégia da escola caso foi o desafio de esclarecer para os futuros pais que a proposta da escola em romper com o modelo tradicional atendia não só à demanda atual do mercado de trabalho, pautado na inovação e na criatividade, mas também à forma de viver e enxergar o mundo das pessoas na atualidade.

A equipe também se empenhou para convencer os pais de que as metodologias ativas adotadas como eixo pedagógico tornariam as aulas mais atrativas e interessantes para essa geração de jovens os quais são nomeados de nativos digitais.

Outro fator trazido pela equipe foi fato de o estado de Pernambuco ser um estado de raízes e tradições muito fortes, o que gera algumas inseguranças nas famílias no sentido de trocar tradição por inovação.

O gerente administrativo/financeiro pontuou que um dos maiores desafios vivenciado por ele foi a troca de público mais exigente. Isso gerou alguns impasses e a administração da escola teve que implantar novas estratégias para a resolução desses. A escola caso promoveu cursos de capacitação sobre atendimento de excelência para os funcionários. Outro ponto levantado pela gerência foi o desafio de não possibilitar política de desconto, o que é muito comum nas instituições concorrentes, o fim dos descontos marcou a mudança de posicionamento. 


\section{CONSIDERAÇÕES FINAIS}

Foi observado que, após a aplicação de novas metodologias por meio das vivências práticas em laboratórios e outros espaços não formais, da realização de projetos, do estabelecimento da prática de sala de aula invertida, os alunos começaram a descrever a satisfação de experienciar um modelo novo de educação em que aluno aprende fazendo, tem voz e protagoniza sua aprendizagem.

Logo, é válido afirmar que as mudanças metodológicas e arquitetônicas foram essenciais para que o projeto pedagógico se tornasse mais enriquecedor e pudesse contribuir para que os professores busquem novas experiências em relação ao exercício da docência.

Assim, ficou também evidente na pesquisa que, não apenas os alunos tiveram ganhos com a mudança, mas também os professores, uma vez que tiveram que retomar os estudos e pesquisas para construção de seus planos de aula, adequando-os às necessidades dos alunos e a uma estrutura que exija maior engajamento e autorresponsabilidade com a aprendizagem.

As mudanças estruturais passaram provocar o corpo docente, a dar asas à criatividade, possibilitando também que seus alunos desenvolvessem a imaginação e a criatividade. A escola caso inseriu em seu currículo várias disciplinas, o que deu a este uma dimensão global.

As inovações não ocorreram apenas no campo da gestão acadêmica, mas também na gestão administrativa da escola. A gerência administrativa buscou um enfoque estratégico e trouxe uma nova forma de gestão para os colaboradores. Treinamentos foram realizados, um novo programa digital de gestão foi implantado, reafirmando o compromisso da diferenciação, por meio da mudança em múltiplas dimensões a fim de se destacar não só na qualidade intrínseca, mas também em um atendimento de qualidade, tanto pelo corpo pedagógico como pela equipe administrativa. Um dos pontos bastante trabalhados foram os cursos de capacitação para equipe de segurança visto ter sido considerado um fator de alta relevância diante do público-alvo da instituição.

Por fim, observou-se um conjunto de fatores integrados que cooperou para o sucesso do empreendimento em seu reposicionamento estratégico. Não sem esforços ou sem resistências, mas pelo contrário, com muito trabalho e persistência de todos que acreditaram no projeto.

\section{REFERÊNCIAS}

Ackerman, C. E. (2019). Big Five Personality Traits: The OCEAN Model Explained. Recuperado em 18 dezembro, 2019, de: https://positivepsychology.com/big-fivepersonality-theory/.

Aithal, P. S., \& Aithal, S. (2015). An innovative education model to realize ideal education system. International Journal of scientific research and management (IJSRM), 3(3), 2464-2469. 
Alves, A. B. (2010). Desenho e uso dos sistemas de controle gerencial e sua contribuição para a formação e implementação da estratégia organizacional. Dissertação de Mestrado, Universidade de São Paulo, São Paulo.

Alves, R. (2019). A escola ideal. Recuperado em 10 novembro, 2019, de: www. todospelaeducacao.org.br.

Anthony, R. N., \& Govindarajan, V. (2006). Sistemas de controle gerencial. São Paulo: Atlas.

Bacich, L., Tanzi Neto, A., \& Mello Trevisani, F. (2015). Ensino híbrido: personalização e tecnologia na educação. Porto Alegre: Penso, 2015.

Baron, N. (2015). Words on screen: The fate of reading in a digital world. Oxford U. Press.

Barros Neto, J. de P. (1999). Proposta de um modelo de formulação de estratégias de produção para pequenas empresas de construção habitacional. Tese de Doutorado em Administração, Universidade Federal do Rio Grande do Sul, Porto Alegre.

Benedet, M. L., Réus, V. B., \& Lunardi, G. M. (2019). A formação continuada de professores da educação básica mediada pelas tecnologias da informação e comunicação. Criar Educação, 8(1). DOI: http://dx.doi.org/10.18616/ce.v8i1.4609.

Conforto, D., Cavedini, P., Miranda, R., \& Caetano, S. (2018). Pensamento computacional na educação básica: interface tecnológica na construção de competências do século XXI. Revista Brasileira de Ensino de Ciências e Matemática, 1(1). DOI: https://doi. org/10.5335/rbecm.v1i1.8481.

Cardoso, R. A. A. N. (2019). Aplicação de tecnologias no processo de ensino e aprendizagem da educação profissional técnica. Ensino em Foco, 2(4), 137-147.

Cortella, M. S. (2014). Educação, escola e docência: novos tempos, novas atitudes. São Paulo: Cortez.

Diniz, J. J. B. (2020). Inovação em uma Sociedade Disruptiva. São Paulo: Novo Século.

Freire, P. (2000). Pedagogia do Oprimido. São Paulo: Paz e Terra.

Flick, U. (2009). Introdução à pesquisa qualitativa (3a ed., J. E. Costa, Trad.). São Paulo: Artmed.

Goleman, D. \& Senge, P. (2015). O foco triplo: uma nova abordagem para a educação. Rio de Janeiro: Objetiva.

INEP. (2019). Censo Escolar 2018. Notas Estatísticas. https://download.inep.gov.br/ educacao_basica/censo_escolar/notas_estatisticas/2018/notas_estatisticas_censo_ escolar_2018.pdf 
Mcgrath, S. (2019). Talk Less So Students Learn More. Edutopia. Recuperado em 16 novembro, 2019, de: https://www.edutopia.org/article/talk-less-so-students-learn-more.

Meira, L. (2017). Escola e inovação educacional no novo mundo do trabalho. Cesar. Recuperado em 15 novembro, 2019, de: https://bit.ly/30S5JNw.

Meyer Jr, V., \& Mugnol, G. (2004). Competição e estratégia no contexto das instituições de ensino superior privadas. Revista Diálogo Educacional, 4(11), 1-13.

Mintzberg, H. (1978). Patterns in Strategy Formation. Management Science, 24(9), 934948. DOI: https://doi.org/10.1287/mnsc.24.9.934.

Mintzberg, H., Ahlstrand, B., \& Lampel, J. (2000). Safari de estratégia: Um Roteiro pela Selva do Planejamento Estratégico. Editora: Bookman.

Mosé, V. (2013). A escola e os desafios contemporâneos. Rio de Janeiro: Civilização Brasileira.

Moran, J. (2015). Mudando a educação com metodologias ativas. Coleção Mídias Contemporâneas. Convergências Midiáticas, Educação e Cidadania: aproximações jovens, 2(1), 15-33.

Nair, Prakash. (2011). The Classroom Is Obsolete: It's Time for Something New. Education Week. Recuperado em novembro, 2019, de: https://bit.ly/3203KHi.

Niskier, A. (2019). Geração 4.0 - Crônicas. Recuperado em 10 novembro, 2019, de: www. arnaldoniskier.com.br.

Pereira, D. N., \& Mendes, M. T. (2019). O uso de "novas" tecnologias na educação básica: interdisciplinaridade e valorização cultural em escolas do campo. EducVale, 1(1), 29-45.

Piangers, M., \& Borba, G. (2019). A escola do futuro: o que querem (precisam) alunos, pais e professores. Porto Alegre: Penso.

Pinto, D. (2019). Descubra o que tem sido feito para promover a inovação na educação. Recuperado em 28 outubro, 2019, de: https://blog.lyceum.com.br/inovacao-naeducacao/.

Porter, M. E. (1986). Estratégia Competitiva: técnicas para análise de indústrias e da concorrência. Rio de Janeiro: Campus.

Sampaio, H. (2011). O setor privado de ensino superior no Brasil: continuidades e transformações. Revista Ensino Superior Unicamp, 4, 28-43.

Tavares, F. G. O. (2019). O conceito de inovação em educação: uma revisão necessária. Educação (UFSM), 44, 4-1-19. DOI: https://doi.org/10.5902/1984644432311. 


\section{Dados dos autores:}

\section{Sandra Cristina Silva Lourette Janguiê}

(iD) ORCID: https://orcid.org/0000-0003-2249-8842

Mestre em Administração pela Universidade da Amazônia. Diretora Geral da Escola Conecta. Recife, Pernambuco, Brasil. E-mail: sandra@escolaconecta.com.

\section{Márcia Athayde Moreira}

(D) ORCID: https://orcid.org/0000-0003-1859-6394

Doutora em Controladoria e Contabilidade. Docente na Universidade Federal do Pará. Belém, Pará, Brasil. E-mail: mathayde@ufpa.br.

\section{Como citar este artigo:}

Janguiê, S. C. S. L. \& Moreira, M. A. (2021). Reposicionamento Estratégico para Diferenciação por Meio da Educação Inovadora. AOS - Amazônia, Organizações e Sustentabilidade, 10(2). http://dx.doi.org/10.17648/aos.v10i2.2498 